as approximately the same number of members of the Society, but the spacious laboratories were not more than pleasantly full. Among the exhibits and experiments, arranged by the boys themselves, were a cathode ray oscillograph, a model geyser, fluorescence in ultra-violet light, a model of a hydraulic ram, the preparation of artificial silk, Bristol's share in the development of chemistry, chemiluminescence, flames and explosions, the effect of plant hormones, living elvers from the Severn, and experiments upon animal respiration. Lectures upon colour and upon liquid oxygen, with demonstrations, were given by two members of the Society, and a third entertained visitors by chemical conjuring performed to the accompaniment of an almost professional patter. The aeronautical section-a comparatively new but already vigorous branch of the Society-staged a topical exhibit of aeroplane parts, including a collection of bombs, while in the Science Library were displayed many scientific classics and autographs of famous men of science. Some of the original quartz glass, made by W. A. Shenstone while at Clifton, was on exhibit in one of the corridors, where a collection of the elements, arranged by a former member of the Society when still at school, also attracted much attention. One of the most popular features of the evening was a tableau vivant of Lavoisier and his wife, after the well-known picture by David. Among the guests were Sir John Inskip, Profs. M. W. Travers, W. E. Garner, C. M. Yonge, R. J. Brocklehurst, A. Rendle Short and A. M. Tyndall, Air Commodore Dalzell-McKean, and the head masters and science masters of many neighbouring schools.

\section{Acquisitions at the British Museum (Natural History)}

The British Museum (Natural History) has received as a donation from Lord Sudeley the skins of three Colobus monkeys from Mount Kenya, Colobus polykomos kikuyuensis. One of the specimens is of exceptional interest, being nearly a full albino, the only black hairs remaining being a few scattered hairs on the back and a small V-shaped marking on the crown of the head. These specimens came from close to Nanyuki, situated on the equator on the western slopes of Mt. Kenya at an elevation of about 8,000-9,000 ft. These white or semi-white Colobus monkeys apparently belong to one family group, as they are all found in one very restricted locality on Mt. Kenya. Lord Sudeley shot the specimens himself and reports that the eyes were of normal colour and not the eyes of an albino. Lord Moyne has presented to the Museum the zoological collections made by M. J. Delacour and Mr. J. S. Colman during the recent cruise of his yacht Rosaura. These include material from the coast of Greenland, southwards to the West Indies, Brazil and the coast of West Africa. The collection when worked out will probably prove of prime importance for several distinct branches of zoological inquiry. The Royal Society has presented a set of specimens of the volcanic rocks of Montserrat in the West Indies, collected by Mr. A. G. MacGregor, who was a member of the Royal Society Expedition which visited the island in 1936 to investigate the causes of the recent earthquake activity and its relation to the vulcanology. A piece of meteoric iron, found last year at Kumerina in Western Australia, has been presented by the Public Library, Museum and Art Gallery at Perth. A polished specimen of 'Brazilian onyz', an ophicalcite worked in the Argentine, has been presented by Messrs. John Bolding and Sons, and the Cookson Lead and Antimony Company has presented a remarkably fine specimen of metallic antimony crystals.

\section{Rubber Technology Conference}

A Rubber Thahnology Conference, under the auspices of the Institution of the Rubber Industry, has been arranged to take place in London on May 23-25, under the honorary presidency of Sir William Bragg. The Conference is being supported by the leading organizations connected with the rubber producing and manufacturing industries and by many other scientific and technical societies; altogether, some seventy organizations in Great Britain, Canada, South Africa, British Malaya, Ceylon, the United States, Austria, Belgium, France, Germany, Holland, Italy and Poland will be sending official delegates to the Conference. These include the Research Association of British Rubber Manufacturers and many of the other industrial research associations operating under the Department of Scientific and Industrial Research. More than seventy papers have already been promised from authors representing most of the countries just mentioned. This excellent response promises to make the Conference an outstanding event, at which a notable gathering of rubber technologists and scientific men interested in rubber from at home and over-seas is expected. A special feature of the Conference will be a symposium on methods of improving and evaluating the durability of rubber, but all other aspects of rubber science and technology will be covered by the remaining sessions. An attractive programme of social events, visits, etc., is being arranged. Those desiring to become members of the Conference or to contribute papers can obtain full particulars from the Secretary, Institution of the Rubber Industry, 12 Whitehall, London, S.W.1.

\section{Oil in Osage County, Oklahoma, U.S.A.}

A FIrid party of the United States Geological Survey has recently investigated sub-surface geology of the Osage Indian Reservation of Oklahoma, and it appears that there are many localities in this Reservation worthy of exploration from the point of view of oil production. Prior to the issue of the Geological Survey's report, a paper had been written by N. W. Bass, W. R. Dillard, and J. H. Hengst (U.S. Department of the Interior. Bull. 886, A) describing several of these localities. In the east. central part of the Reservation, it is believed there may be an oil pool of considerable extent in the Bartesville Sand. Three productive wells have already been drilled. One drilled thirteen years ago had produced 63,000 barrels of oil by the end of (Continued on p. 599) 
July 1936, and is still producing at the rate of approximately 10 barrels a day. Another situated half a mile south-east gave a 30-barrel show of oil in the Bartesville Sand in 1922; and a third, a considerable distance to the north-east of the other two, produced about 25 barrels of oil in 1921. The presence of productive oil sand in these three wells points to the probability that oil-bearing Bartesville Sand occurs in this district in a characteristic lens-shaped body. In addition, there are known to be in the Reservation two small domes, as yet untested, but structurally similar to two nearby domes producing from the Siliceous Lime. The productive domes are fairly typical of the oil fields, being of small extent but giving large yields. On one of these there are eight wells which have yielded oil, and on the other five. The approximate yield per acre of the former dome up to July 1936 was 6,964 barrels of oil, and of the latter, for the same period, 6,300 barrels. Recently, also, the rate of yield from both domes has been materially increased by treating the oil-bearing beds in the upper part of the Siliceous Lime with hydrochloric acid.

\section{Plastics and Insulation}

A JorNT meeting of the Institution of Electrical Engineers and the Plastics Group of the Society of Chemical Industry was held at the Institution of Electrical Engineers on March 24 to discuss a paper on "Plastics and Insulation" by L. Hartshorn, N. J. L. Megson and E. Rushton. It is largely based on an investigation carried out at the National Physical Laboratory and the Chemical Research Laboratory for the British Electrical and Allied Industries Research Association. Broadly speaking, a plastic is any material from which rigid objects of predetermined shape may be made by moulding processes. Their most characteristic property is that by suitable treatment they may be made to pass through a plastic condition, that is, a state between the solid and liquid states, like that of dough or damp clay. The property of hardening instead of softening on the application of heat is one of considerable practical importance to both moulders and users of plastics. It increases the working temperature of the material and improves its mechanical properties. It also allows the finished article to be removed from the mould while still hot. The primary function of an electrical insulating material (a dielectric) is to act as a barrier to the flow of electricity. Dielectrics always pass a leakage current, sometimes through the body of the material and sometimes over its surface. These currents can be taken as a measure of a defect of the material. With alternating current we have in addition an expenditure of energy due to the pulsating current in the dielectric. Polystyrene and polyindene, materials not yet produced in Great Britain, are hydrocarbon plastics, made in the form of clear glass, like solids, and are almost ideal for use in cables for high-frequency work ; for example, in television, and in ultra-shortwave radio work, and in junctions for high-voltage cable work they are almost ideal.

\section{Report on Street Lighting}

DR. J. W. T. WALSH gave an introductory account to the Illuminating Engineering Society on February 8 of the final report of the Ministry of Transport Committee. It was then discussed by the Society and the discussion is published in the February issue of Light and Lighting. The members constituting the Committee were the chairman, four lighting specialists, two engineers associated with local authorities and two Government officials. Its final report was issued in November 1937. The Committee received evidence from several organizations and made inspections of a large number of existing installations. It also carried out experimental work on a special roadway (Lonsdale Road, Barnes) set aside for the purpose. The Committee classified roads into two groups only, $A$ and $B$, and gave technical recommendations for each group. In the recom mendations the Committee insisted on the importance of satisfactory maintenance and approved of light. ing from dusk to dawn. Whilst it was recognized that special study of measures for the guidance of traffic during fog was necessary, it was urged that the general design of installations should not be prejudiced by special adaptation to fog conditions. The report also recommends that a formal specification for street lighting should be issued without delay by the British Standards Institution. In conclusion, Dr. Walsh showed a film of a lighted street just as it would appear in practice, in which various objects (persons stepping into the roadway, dogs, etc.) were continually coming into view and then disappearing. The number of such disappearances was stated to be fifty-six. But very few of the observers succeeded in identifying half this number. This showed the danger of bad lighting.

\section{Journal of Neurophysiology}

THE new Journal of Neurophysiology, under the editorship of Prof. Dusser de Barenne, J. F. Fulton and R. W. Gerard, made its first appearance in January. It is designed primarily to provide a means of publishing papers dealing with the experimental analysis of the phenomena of the central and peripheral nervous system, and descriptive neuroanatomy and pathology are intentionally excluded. The publisher, Thomas of Springfield, Illinois, intends to produce a number every other month, and the editorial board undertakes to deal with submitted papers within one or two months of receipt. This accelerated publication is certainly desirable, as the existing channels for the publication of papers in this field in the United States are overcrowded, and there is an inevitable delay. The first number, of 55 pages, contains nine papers dealing, inter alia, with cerebral action potentials, effects of experimental cerebral lesions, degeneration of nerve, and changes in the salt content of nerves as a result of the transmission of impulses. The format is pleasing, and the standard of the illustrations is high. A little more uniformity in certain details is desirable; authors are cited in different papers either by numbers, by year or by an abbreviation of the year ; the date of 